
preparo do solo. Horticultura Brasileira 25:355-359.

\title{
Características físicas do solo e produtividade da batata dependendo de sistemas de preparo do solo
}

\author{
Paulo Cezar Rezende Fontes ${ }^{1,3}$; Julio Cezar Silveira Nunes ${ }^{1,4}$; Haroldo Carlos Fernandes²; Eduardo \\ Fontes Araújo ${ }^{1,3}$
}

${ }^{1}$ UFV-Depto. Fitotecnia, 36570-000 Viçosa-MG; ${ }^{2}$ UFV-Depto. Engenharia Agrícola, 36571-000 Viçosa-MG; ${ }^{3}$ Bolsistas CNPq; ${ }^{4}$ Bolsista FAPEMIG; pacerefo@ufv.br

\section{RESUMO}

Foi avaliado o efeito de sistemas de preparo do solo sobre o diâmetro médio dos agregados (DMA), porcentagem de cobertura da superfície do solo (CSS), profundidade da camada arada (PCA) e produção de tubérculos de batata. Foram instalados dois experimentos em solo argiloso com os mesmos tratamentos, sendo um irrigado por gotejamento e outro por aspersão. Os tratamentos foram: T1 = apenas abertura do sulco de plantio, prática comum aos demais tratamentos; T2 = uma subsolagem (SS); T3 = duas passadas de enxada rotativa (ER); T4 = uma aração com disco (AD) + duas gradagens niveladoras $(\mathrm{GN}) ; \mathrm{T} 5=1 \mathrm{AD}+2 \mathrm{GN}+1 \mathrm{ER} ; \mathrm{T} 6=1 \mathrm{AD}+2 \mathrm{GN}+$ 2ER; T7 = 1SS + a sequencia de T6; T8 = uma aração com aiveca (AA) + 2GN. Os tratamentos foram distribuídos em blocos ao acaso com quatro repetições e o plantio foi manual. Os maiores valores de DMA e de CSS foram observados em T1 e T2 e o maior valor de PCA, 29,6 cm, foi observado em T8. Em ambos experimentos, a produção de tubérculos comerciais (PCT) foi maior em T8, menor em T1 e T2 e intermediária nos demais tratamentos. Na média dos experimentos, o aumento médio da PCT pela aração com aiveca (T8) foi 52\% em relação ao disco (T4).

Palavras-chave: Solanum tuberosum, plantio direto, conservação de solo, aiveca, enxada rotativa, gotejamento, aspersão.

\begin{abstract}
Soil physical characteristics and potato yield as affected by soil tillage systems

The effects of soil tillage systems were evaluated on soil aggregate mean diameter (DMA), soil surface cover (CSS), deepploughed soil layer (PCA) and potato tuber yield. Two experiments, one sprinkle-irrigated and the other drip-irrigated, were conducted in a clay soil with the same treatments. The treatments were: $\mathrm{T} 1=$ no tillage, except furrowing before planting, also performed in the other treatments; $\mathrm{T} 2$ = one sub soiling (SS); $\mathrm{T} 3$ = twice rotary hoeing (ER); T4 = one disc plowing (AD) + twice disc harrow leveling $(\mathrm{GN}) ; \mathrm{T} 5=1 \mathrm{AD}+2 \mathrm{GN}+1 \mathrm{ER} ; \mathrm{T} 6=1 \mathrm{AD}+2 \mathrm{GN}+2 \mathrm{ER} ; \mathrm{T} 7=1 \mathrm{SS}$ $+\mathrm{T} 6$ sequence; $\mathrm{T} 8=$ one moldboard plowing $(\mathrm{AA})+2 \mathrm{GN}$. Treatments were arranged in a randomized block design with four replications. Planting was manually performed, in previously open furrows. The highest DMA and CSS values were obtained at T1 and T2 and the highest PCA value, $29.6 \mathrm{~cm}$, was observed at T8. In both experiments, commercial tuber yield was the largest in T8, the smallest in $\mathrm{T} 1$ and $\mathrm{T} 2$, and intermediate in the remaining treatments. In both experiments, the commercial tuber yield increased 52\% due to moldboard plow (T8) in comparison to disk plow (T4).
\end{abstract}

Keywords: Solanum tuberosum, direct seeding, soil conservation, moldboard, rotary hoe, drip, sprinkle.

\section{(Recebido para publicação em 14 de fevereiro de 2006; aceito em 31 de agosto de 2007)}

$\mathrm{O}$ preparo convencional do solo para cultura da batata, normalmente, envolve aração com a utilização do arado de disco, gradagens e, às vezes, passada de enxada rotativa em intensidade que dependo do tipo de solo (Fontes, 1997). É prática comum entre os bataticultores a utilização de sistema de preparo que mobiliza intensa camada superficial do solo, podendo favorecer a erosão (Mesquita et al.,1999). Essa, além de causar dano ambiental, reduz o potencial produtivo do solo (Araujo \& Fontes, 2003), causa prejuízo econômico e compromete a viabilidade da cultura (Boller et al., 1998), principalmente pela redução na taxa de infiltração de água, na porosidade e na quantidade de água disponível (Rachwall \& Dedecek, 1996).

Em geral, o preparo inadequado do solo resulta em compactação, remoção da camada superficial do solo, assoreamento dos cursos de água e destruição de margens de rios, reservatórios e córregos. Isto ocorre em razão da destruição dos agregados do solo, tornando as partículas menores e mais dispersas. A evolução do diâmetro médio dos agregados demonstra o processo de degradação física do solo imposto pelos cultivos realizados. Nesse sentido, o preparo intensivo reduz o valor do diâmetro dos agregados por efeito mecânico e, ou, pela rápida perda da matéria orgânica do solo e dos restos culturais (Barbosa et al.,1998).

Mudanças significativas estão ocorrendo em relação ao cuidado com o meio ambiente e manutenção dos recursos naturais, havendo forte questionamento sobre a perda de solo por erosão e da necessidade de intensa mobilização no preparo do solo. O cultivo mínimo ou preparo reduzido coloca-se em posição intermediária ao preparo convencional do solo e o plantio direto. O cultivo mínimo e o semeio direto são chamados de preparos conservacionistas que objetivam economizar energia, propiciar estabilidade do solo, reduzir a erosão e tornar a agricultura sustentável. Entretanto, o preparo do solo precisa apresentar eficiência econômica e aceitabilidade (Sturz et al., 1997). Segundo os autores, a inconstância do efeito de doenças (positivo, negativo e sem efeito) é considerada um dos maiores impedimentos para a total utilização do preparo conservacionista do solo.

Na cultura da batata, principalmente em outros países, preocupa-se em reduzir a degradação do solo que pode, em parte, ser obtida por meio do prepa- 
ro com menor número de operações com máquinas. A preocupação com os exageros verificados no preparo e a intenção de obter o maior nível de retenção de água na área tem levado pesquisadores a buscarem sistema alternativos de preparo do solo como a aração em faixa (Pierce \& Burpee, 1995), aração reduzida (Alva et al., 2002), preparo inicial de toda a área com escarificador ao invés do arado de aiveca (Carter \& Sanderson, 2001), entre outros. Neste contexto, o plantio direto e o cultivo mínimo, amplamente divulgados e utilizados por produtores de grãos, podem ser uma possibilidade na cultura da batata.

O plantio direto da batata não é realizado em ampla escala comercial. Porém, experimentalmente, na Noruega, em solo arenoso, Ekeberg \& Riley (1996) mostraram a viabilidade do plantio direto da batata em restos de cultura de cevada, utilizando-se uma plantadora adaptada. No Brasil, Boller \& Prediger (2000) mostraram ser possível o plantio da batata em camalhão previamente construído. Outros autores mostraram a viabilidade do preparo de solo reduzido e plantio direto na cultura da batata plantada mecanicamente (Alva et al., 2002; Oliveira, 2003).

No Brasil, os trabalhos sobre preparo do solo e desempenho da cultura da batata são escassos (Fontes, 2005). Menos freqüentes são as pesquisas envolvendo a avaliação de sistemas conservacionistas de preparo do solo para o plantio manual da batata. Neste trabalho avaliou-se o efeito de sistemas de preparo do solo sobre a profundidade da camada arada (PCA), diâmetro médio dos agregados (DMA), porcentagem de cobertura da superfície do solo (CSS) e produção de tubérculos de batata.

\section{MATERIAL E MÉTODOS}

Foram instalados dois experimentos, um irrigado por gotejamento e o outro por aspersão em áreas contíguas e de reduzida declividade, na Horta Experimental da UFV. Essas áreas, ao longo do tempo vêm sendo preparadas convencionalmente com arado e grade de discos e cultivadas com hortaliças. Nos últimos três anos estava plantada com mucuna preta (Stylozobium aterrimum) $e$ dois meses e meio antes do plantio foi pulverizada com Glifosato. Adicionalmente, 30 e 20 dias antes do plantio, respectivamente, as áreas foram roçadas mecanicamente e pulverizadas com Glifosato. O solo foi classificado como Argissolo Vermelho-Amarelo Câmbico; argiloso; 1,46 MPa de resistência à penetração; $1,26 \mathrm{~kg} \mathrm{dm}^{-3}$ de densidade;

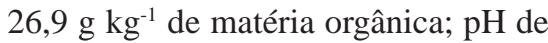
5,2 e CTC de $10,0 \mathrm{cmol}_{\mathrm{c}} \mathrm{dm}^{-3}$.

Nos dois experimentos foram avaliados oito tratamentos: T1= nenhum preparo do solo exceto o sulcamento antes do plantio, operação também realizada nos demais tratamentos; $\mathrm{T} 2=$ uma subsolagem (SS); T3= uma passada de enxada rotativa (ER); T4= uma aração com arado de discos (AD) + duas gradagens com grade niveladora/ destorroadora $(\mathrm{GN})$; $\mathrm{T} 5=1 \mathrm{AD}+2 \mathrm{GN}$ $+1 \mathrm{ER} ; \mathrm{T} 6=1 \mathrm{AD}+2 \mathrm{GN}+2 \mathrm{ER} ; \mathrm{T} 7=$ 1SS + a seqüência do tratamento 6; T8 $=1 \mathrm{AA}+2 \mathrm{GN}$. A subsolagem foi realizada, aproximadamente, a $45 \mathrm{~cm}$ de profundidade nos locais das duas fileiras centrais de plantas. O delineamento estatístico foi em blocos ao acaso, com oito tratamentos e quatro repetições. Cada parcela continha quatro linhas de plantas, espaçadas $0,75 \mathrm{~m}$ e de $6,2 \mathrm{~m}$ de comprimento.

A adubação constou de $4000 \mathrm{~kg} \mathrm{ha}^{-1}$ do adubo 4-14-8, $10 \mathrm{~kg} \mathrm{ha}^{-1}$ de bórax, $200 \mathrm{~kg} \mathrm{ha}^{-1}$ de sulfato de magnésio e inseticida organofosforado sistêmico colocados no sulco de plantio. Após a aplicação, foram plantadas, manualmente, batatas-semente "filha de caixa", previamente brotadas, com peso médio de 50 $\mathrm{g}$ da cultivar Monalisa. A profundidade de plantio foi $0,10 \mathrm{~m}$ e o espaçamento $0,31 \mathrm{~m}$. No experimento irrigado por aspersão, foram gastos 386 mm de água e não houve precipitação pluviométrica no período. No experimento irrigado por gotejamento, a fita gotejadora foi colocada ao longo de cada fileira, após o plantio. Antes da amontoa, a fita foi deslocada da posição original e, após a amontoa, a fita foi deslocada, ficando situada a $15 \mathrm{~cm}$ de distancia da fileira de plantas, isto é, não permaneceu em cima da leira formada pela amontoa. Durante o ciclo foram gastos $266 \mathrm{~mm}$ de água, em aplicações a cada quatro dias seguindo-se em parte o procedi- mento adotado por Fabeiro et al. (2001).

Após o plantio, no experimento irrigado por aspersão, foram coletadas amostras na camada de solo arado, para a determinação do diâmetro médio dos agregados (DMA), segundo metodologia da EMBRAPA (1997). Também, foi avaliada a porcentagem de cobertura da superfície do solo (CSS), seguindo a metodologia de Sloneker \& Moldenhauer (1977).

Pouco antes do fechamento das fileiras, aos 37 dias após o plantio, foi feita a adubação de cobertura, com 810 kg $\mathrm{ha}^{-1}$ de sulfato de amônio que foi aplicado no lado da fileira de plantas em que estava a fita gotejadora e nos dois lados da planta no experimento irrigado por aspersão. Em seguida, com enxada, foi feita a amontoa. Após a amontoa, apenas no experimento irrigado por aspersão, foi determinada a profundidade da camada de solo arada (PCA), medida a partir do topo do camalhão formado pela amontoa, sendo considerada igual a zero a PCA nos tratamentos T1 e T2.

Durante o ciclo foram feitas pulverizações com fungicidas e inseticidas de forma preventiva. Aos 104 dias após o plantio, quando a parte aérea das plantas estava seca, foi realizada a colheita dos tubérculos. Nos dois experimentos, os tubérculos foram colhidos nas duas fileiras centrais da parcela. Os tubérculos foram deixados no local por 24 horas, para secar a película e em seguida transportados para galpão onde foram avaliados e separados em comerciais e não comerciais ( $<20 \mathrm{~mm}$, rachados, embonecados e esverdeados). Os tubérculos foram inspecionados visualmente quanto à presença de sintomas de Rhizoctonia solani e sarna (Streptomyces spp.).

As variáveis dependentes foram analisadas em cada experimento separadamente pelo teste de Newman Keuls, a 5 \% de significância e a produção de tubérculos comerciais e totais foram também comparadas pela análise conjunta dos dois experimentos.

\section{RESULTADOS E DISCUSSÃO}

Os maiores valores do diâmetro médio dos agregados (DMA), 0,91 e $0,95 \mathrm{~mm}$, foram observados nos trata- 
mentos T1 e T2, respectivamente (Tabela 1) indicando maior capacidade de preservar a estabilidade dos agregados do que os tratamentos envolvendo o preparo convencional onde ocorreu operação de revolvimento profundo seguida por preparo superficial do solo. A subsolagem (T2) não diminuiu o DMA do solo e o inverso ocorreu em T3 com a enxada rotativa (Tabela 1 ). Boller \& Prediger (2000) observaram que o menor DMA e a maior produção de tubérculos comerciais foram obtidos no tratamento onde o solo foi preparado de modo convencional, arado de disco e duas passadas de grade niveladora/ destorroadora. No referido tratamento houve mais intenso revolvimento do solo do que nos tratamentos onde foi realizado o plantio direto em camalhões, construídos na época do plantio da cultura de cobertura, e onde o solo foi submetido ao preparo mínimo, escarificação e uma passada de rolo destorroador.

Considerando os tratamentos onde houve revolvimento do solo (T3 até T8), onde foi utilizada apenas a enxada rotativa (T3) ocorreu o menor valor de profundidade da camada de solo arada (PCA), 16,9 cm (Tabela 1). Segundo Silveira (1997), os valores da PCA decrescem de 15, 20 e $30 \mathrm{~cm}$ ao ser utilizada a enxada rotativa, arado de disco e arado de aiveca, respectivamente. Nos últimos 20 anos, o solo utilizado no presente experimento tem sido preparado por modo tradicional, com arado de discos, com as operações realizadas continuamente numa mesma profundidade podendo ter ocasionado a formação de camada compactada, pé-de-arado e péde-grade, resultante da pressão do arado e da grade sobre o solo.

A cobertura da superfície do solo (CSS) variou de 4,1\% em T7 a 68,9 \% em T1 (Tabela 1). Isto é, diminuiu com o aumento das operações de preparo do solo. A cobertura vegetal permaneceu na superfície do solo até a operação de amontoa que concentrou a palhada na fileira das plantas. A CSS tem importância por conservar a umidade do solo por mais tempo. Mundy et al. (1999) observaram que o plantio direto comparado com sistemas de cultivo mínimo e preparo convencional do solo con-

Tabela 1. Diâmetro médio dos agregados do solo (DMA), profundidade da camada de solo arada (PCA) e porcentagem de cobertura da superfície do solo (CSS) nos tratamentos do experimento irrigado por aspersão. (Soil aggregate mean diameter (DMA), deep-ploughed soil layer (PCA) and soil surface cover (CSS) of the treatments in the sprinkle-irrigated experiment). Viçosa, UFV, 2005.

\begin{tabular}{lccc}
\hline Tratamentos $^{1}$ & DMA (mm) & PCA (cm) & CSS (\%) \\
\hline $\mathrm{T}=\mathrm{NP}^{1}$ & $0,91 \mathrm{a}$ & $0 \mathrm{~d}$ & $68,9 \mathrm{a}$ \\
$\mathrm{T} 2=1 \mathrm{SS}$ & $0,95 \mathrm{a}$ & $0 \mathrm{~d}$ & $51,3 \mathrm{~b}$ \\
$\mathrm{~T} 3=2 \mathrm{ER}$ & $0,77 \mathrm{~b}$ & $16,9 \mathrm{c}$ & $30,1 \mathrm{c}$ \\
$\mathrm{T} 4=1 \mathrm{AD}+2 \mathrm{GN}$ & $0,68 \mathrm{~b}$ & $24,4 \mathrm{~b}$ & $17,6 \mathrm{~cd}$ \\
$\mathrm{~T} 5=1 \mathrm{AD}+2 \mathrm{GN}+1 \mathrm{ER}$ & $0,69 \mathrm{~b}$ & $25,6 \mathrm{ab}$ & $16,8 \mathrm{~cd}$ \\
$\mathrm{~T} 6=1 \mathrm{AD}+2 \mathrm{GN}+2 \mathrm{ER}$ & $0,72 \mathrm{~b}$ & $23,9 \mathrm{~b}$ & $5,6 \mathrm{~d}$ \\
$\mathrm{~T} 7=1 \mathrm{SS}+1 \mathrm{AD}+2 \mathrm{GN}+2 \mathrm{ER}$ & $0,64 \mathrm{~b}$ & $25,5 \mathrm{ab}$ & $4,1 \mathrm{~d}$ \\
$\mathrm{~T} 8=1 \mathrm{AA}+2 \mathrm{GN}$ & $0,78 \mathrm{~b}$ & $29,6 \mathrm{a}$ & $28,5 \mathrm{c}$ \\
\hline
\end{tabular}

${ }^{1} \mathrm{NP}=$ nenhum preparo do solo; $1 \mathrm{SS}=$ uma subsolagem; $2 \mathrm{ER}$ = duas passadas de enxada rotativa; $1 \mathrm{AD}$ = uma aração com arado de disco; $2 \mathrm{GN}$ = duas gradagens com grade niveladora/ destorroadora; 1AA = uma aração com arado de aiveca; Médias na coluna seguidas de uma mesma letra não diferem entre si a 5\% de probabilidade pelo teste de Newman Keuls $\left({ }^{1} \mathrm{NP}=\right.$ no soil tillage; $1 \mathrm{SS}$ = one subsoiling; $2 \mathrm{ER}$ = twice rotary hoeing; $1 \mathrm{AD}=$ one disc plowing; 2GN = twice disc harrow leveling; 1AA = one moldboard plowing; means followed by the same letter in the column did not differ from each other by the Newman Keuls test, $\mathrm{P}<0.05$ ).

servou mais palhada na superfície e reteve mais umidade no solo, beneficiando a cultura da batata em condição de deficiência hídrica. Esses autores encontraram valores de 3; 45 e 58\% para CSS na cultura da batata para os sistemas de preparo do solo convencional (uma gradagem com grade pesada e uma gradagem com grade niveladora/ destorroadora), mínimo (escarificação do solo) e direto (plantio sem preparo do solo). Também, em outras culturas, observou-se decréscimo em CSS com o aumento das operações de preparo de solo (Sloneker \& Moldenhauer, 1977).

O valor de CSS ultrapassou 30\% nos tratamentos T1, T2 e T3 (Tabela 1). O sistema de cultivo do solo que permite a manutenção de no mínimo 30\% da superfície do solo coberta com resíduos, durante o período que sucede a colheita da cultura anterior, até a implantação da cultura seguinte, pode ser denominado conservacionista (Magleby \& Schertz, 1988). O sistema de cultivo conservacionista mantém considerável quantidade de resíduo na superfície do solo, protegendo-o contra o impacto direto das gotas de água da chuva e da irrigação (Castro Filho et al.,1991).

Em nenhum tratamento, nos dois experimentos, foram verificados sintomas de rizoctônia e sarna nos tubérculos. Em ambos experimentos, verificou- se a maior produção de tubérculos comerciais em T8 onde a aração foi realizada com o arado de aiveca (Tabela 2). No experimento irrigado por gotejamento, o aumento de produtividade de tubérculos comerciais pela utilização do arado de aiveca foi 60\% (T8) em relação ao tratamento em que se utilizou o arado de discos (T4); o valor correspondente no experimento irrigado por aspersão foi $44 \%$. Em ambos experimentos, nos tratamentos com o uso do arado de discos (T4, T5, T6 e T7), a produtividade média de tubérculos comerciais foi apenas $71 \%$ daquela obtida no tratamento onde o solo foi arado com aiveca (T8). O ato de tornar o solo mais solto em camadas profundas propicia aumento de produtividade da batata em solo compactado (Saini \& Hughes, 1972), apesar de alguns resultados experimentais indicarem que o preparo profundo não é necessário em todas as condições (Parker et al., 1989). Também, é comum o aumento da produtividade das culturas pelo uso da aração com aiveca, principalmente quando comparada com a grade aradora (Arf et al., 2001), provavelmente devido ao maior volume de solo preparado disponível às raízes. Entretanto, segundo Riley \& Ekeberg (1998) o efeito benéfico da aração com aiveca sobre a produção de batata decresce com o decréscimo na camada arada de solo. 
Tabela 2. Produção total (PT) e comercial (PC) de tubérculos nos tratamentos, nos experimentos irrigados por gotejamento e por aspersão. (Total and marketable potato tuber yield in the sprinkle and drip-irrigated irrigated experiments). Viçosa, UFV, 2005.

\begin{tabular}{|c|c|c|c|c|}
\hline \multirow{2}{*}{ Tratamentos $^{1}$} & \multicolumn{2}{|c|}{ Gotejamento (t ha-1) } & \multicolumn{2}{|c|}{ Aspersão (t ha-1) } \\
\hline & PT & PC & PT & PC \\
\hline $\mathrm{T} 1=\mathrm{NP}^{1}$ & 27,6 & $23,0 d$ & $31,9 \mathrm{c}$ & $27,2 \mathrm{c}$ \\
\hline $\mathrm{T} 2=1 \mathrm{SS}$ & 35,3 & $26,4 \mathrm{c}$ & $31,1 \mathrm{c}$ & $25,8 \mathrm{c}$ \\
\hline $\mathrm{T} 3=2 \mathrm{ER}$ & 31,4 & $28,2 \mathrm{c}$ & $30,9 \mathrm{c}$ & $26,9 \mathrm{c}$ \\
\hline $\mathrm{T} 4=1 \mathrm{AD}+2 \mathrm{GN}$ & 30,6 & $25,9 \mathrm{c}$ & $38,0 \mathrm{bc}$ & $33,0 \mathrm{bc}$ \\
\hline$T 5=1 A D+2 G N+1 E R$ & 35,3 & $30,8 \mathrm{~b}$ & $36,2 \mathrm{bc}$ & $32,2 \mathrm{bc}$ \\
\hline$T 6=1 A D+2 G N+2 E R$ & 34,3 & $30,6 \mathrm{~b}$ & $35,5 \mathrm{bc}$ & $32,7 \mathrm{bc}$ \\
\hline$T 7=1 S S+1 A D+2 G N+2 E R$ & 34,7 & $31,1 \mathrm{~b}$ & $41,8 \mathrm{~b}$ & $36,8 \mathrm{~b}$ \\
\hline$T 8=1 A A+2 G N$ & 46,3 & $41,5 a$ & 52,5 a & $47,4 a$ \\
\hline
\end{tabular}

${ }^{1} \mathrm{NP}=$ nenhum preparo do solo; $1 \mathrm{SS}$ = uma subsolagem; $2 \mathrm{ER}$ = duas passadas de enxada rotativa; $1 \mathrm{AD}=$ uma aração com arado de disco; $2 \mathrm{GN}$ = duas gradagens com grade niveladora/ destorroadora; $1 \mathrm{AA}$ = uma aração com arado de aiveca; Médias na coluna seguidas de uma mesma letra não diferem entre si a $5 \%$ de probabilidade pelo teste de Newman Keuls $\left({ }^{1} \mathrm{NP}\right.$ = no soil tillage; $1 \mathrm{SS}$ = one subsoiling; $2 \mathrm{ER}=$ twice rotary hoeing; $1 \mathrm{AD}=$ one disc plowing; $2 \mathrm{GN}$ = twice disc harrow leveling; $1 \mathrm{AA}=$ one moldboard plowing; means followed by the same letter in the column did not differ from each other by the Newman Keuls test, $\mathrm{P}<0.05$ ).

Em ambos experimentos, em solo preparado com arado de disco e enxada rotativa (T5, T6 e T7), não foi verificado efeito significativo da subsolagem (T7) sobre a produtividade de turbérculos comerciais (Tabela 2). No experimento irrigado por gotejamento, a subsolagem (T2) propiciou aumento de $15 \%$ na produção de tubérculos comerciais em relação a T1 onde o solo foi apenas sulcado (Tabela 2). Semelhante efeito não foi verificado na cultura irrigada por aspersão. A subsolagem quebra a camada campactada do solo, permitindo que a raiz se desenvolva livremente (Miller \& Martin, 1987). Em dois solos argilosos, esses autores verificaram que as plantas ficaram maiores, houve expansão do sistema radicular, o fechamento do dossel entre as linhas de plantio ocorreu mais cedo e houve aumento de $60 \%$ na produção de tubérculos de batata da classe especial nas parcelas onde o solo foi subsolado em comparação com aquelas em que o solo não foi submetido à subsolagem.

Nos tratamentos onde não foi feita a aração (T1, T2 e T3), isto é, foi adotado o plantio direto e o cultivo mínimo, a produtividade média de tubérculos comerciais, nos experimentos irrigados por gotejamento e aspersão, foi apenas 62 e $56 \%$, respectivamente daquela obtida no melhor tratamento T8 (Tabela 1), onde o solo foi convencionalmente prepara- do com arado de aiveca. Menor produção de outras culturas foi verificada em semeio direto comparado com o plantio em solo arado e gradeado em razão da menor porosidade total e estrutura da superfície do solo que proporcionaram menor volume de exploração das raízes e movimentação de água (Schmidt \& Belford, 1994; Ferreras et al., 2001). Maior produção total de tubérculos de batata no sistema de plantio direto foi obtida em época de déficit hídrico (Pierce \& Burpee, 1995); sem ocorrer déficit hídrico não houve diferença na produção de tubérculos comerciais de batata entre os sistemas de plantio sem o revolvimento do solo e o preparo convencional, uma aração com arado de disco e duas passadas com a grade niveladora-destorroadora.

No presente trabalho, realizado em solo argiloso, o plantio direto (T1) não propiciou produtividade de tubérculos de batata semelhante ao obtido com o preparo convencional do solo, diferentemente do obtido por outros autores (Dallyn \& Fricke, 1974; Ekeberger \& Riley, 1996; Mundy et al., 1999) em experimentos realizados em solo arenoso e plantio mecanizado. Plantio e amontoa mecanizados da batata influenciam características físicas da camada subsuperficial do solo, podendo beneficiar o plantio direto, principalmente em solo pouco argiloso.
Na análise conjunta dos experimentos, verificou-se que a interação entre os fatores irrigação e tratamento não foi significativa. Na média dos oito tratamentos, a irrigação por aspersão propiciou produção comercial de tubérculos $\left(32,8\right.$ t ha $\left.^{-1}\right)$ significativamente maior do que a irrigação por gotejamento $(29,7 \mathrm{t}$ $h^{-1}$ ); para a produção total os valores correspondentes foram 37,3 e 34,4 $\mathrm{t} \mathrm{ha}^{-1}$, respectivamente.

A eficiência de utilização da água (kg de tubérculos produzidos/mm de água aplicada) foi maior no experimento irrigado por gotejamento. Para Darwish et al. (2003), a irrigação por gotejamento da batateira pode ser considerada uma prática cultural conservacionista do meio ambiente, pois proporciona menor lixiviação de nitrato para o lençol freático em comparação com a irrigação por aspersão. Na irrigação por gotejamento, a relação entre a quantidade de água e a produção de tubérculos pode ser expressa por $\mathrm{Y}=$ - 409,47 + 7,52X - 0,0092X $X^{2}$ onde X é a quantidade de água expressa em mm e Y a produção total, em g de tubérculos por planta (Yuan et al., 2003). Os autores conseguiram para a produção máxima, 1127 g planta $^{-1}$, o valor de X igual a $409 \mathrm{~mm}$ ou seja, $1 \mathrm{~mm}$ de água produziu 2,76 g planta-1 ${ }^{-1}$ No presente experimento irrigado por gotejamento, onde foram gastos 266 mm de água, a produtividade comercial de tubérculos obtida em T8 foi 41,5 t ha-1 ou 965 g planta $^{-1}$. Portanto, $1 \mathrm{~mm}$ de água proporcionou a obtenção de 3,63 g planta ${ }^{-1}$ ou 156 kg de tubérculo comercial. Assim, a eficiência do uso da água no presente experimento foi 32 e $122 \%$ maior do que as obtidas por Yuan et al. (2003) e Fabeiro et al. (2001), respectivamente, em experimentos com a batateira irrigada por gotejamento.

Concluiu-se que tanto em cultura irrigada por aspersão quanto por gotejamento o sistema de preparo do solo influencia a profundidade da camada arada (PCA), diâmetro médio dos agregados (DMA), porcentagem de cobertura da superfície do solo (CSS) e a produção de tubérculos de batata. $\mathrm{O}$ sistema constando de aração com aiveca e duas gradagens proporciona maior profundidade da camada arada e maior pro- 
dutividade de tubérculos comerciais do que os demais sistemas.

\section{AGRADECIMENTOS}

Ao CNPq pela bolsa de produtividade e À FAPEMIG pela bolsa de pósgraduação.

\section{REFERÊNCIAS}

ALVA AK; HODGES T; BOYDSTON RA; CALLINS HP. 2002. Effects of irrigation and tillage practices on yield of potato under high production conditions in the Pacific Northwest. Communication Soil Science Plant Analysis 9:1451-1460.

ARAUJO C; FONTES PCR. 2003. Produção de batata em solo erodido, em função de dose de nitrogênio. Horticultura Brasileira 21: 370.

ARF O; RODRIGUES RAF; SA ME; CRUSCIOL CAC. 2001. Resposta de cultivares de arroz de sequeiro ao preparo do solo e à irrigação por aspersão. Pesquisa Agropecuária Brasileira 36: 871-879.

BARBOSA Z; BAHIA VG; PAULA MB. 1998 Atuação da biota do solo na formação e estabilização de agregados e na estruturação dos solos, influenciando o controle da erosão. Informe Agropecuário 19: 59-65.

BOLLER W; PREDIGER AJ; KLASSMANN V. 1998. Sistema de preparo de solo para implantação da cultura da batata (Solanum tuberosum). In: CONGRESSO BRASILEIRO DE ENGENHARIAAGRÍCOLA, 27. Anais... Lavras: UFLA/SBEA, Volume 3, p. 175-177.

BOLLER W; PREDIGER LJ. 2000. Cultivo mínimo e plantio direto de batata após diferentes condições de cobertura do solo. In: CONGRESSO BRASILEIRO DE ENGENHARIA AGRÍCOLA, 29. Anais... Fortaleza: SBEA (CD-ROM)

CARTER MR; SANDERSON JB. 2001. Influence of conservation tillage and rotation length on potato productivity, tuber disease and soil quality parameters on a fine sandy loam in eastern Canada. Soil \& Tillage Research 63: 1-13.

CASTRO FILHO C; HENKLAN JC; VIEIRA MJ; DASÃO R. 1991. Tillage methods and soil and water conservation in Southern Brazil. Soil \& Tillage Research 271-283.
DALLYN SL; FRICKE DH. 1974. The use of minimum tillage plus herbicides in potato production. American Potato Journal 51: 177184

EMBRAPA: 1997. Manual de métodos de análise de solo. Rio de Janeiro: Serviço Nacional de Levantamento e Conservação de Solos. 212p.

DARWISH T, ATALLAH T, HAJHASAN S, CHRANEK A. 2003. Management of nitrogen by fertigation of potato in Lebanon. Nutrient Cycling in Agroecosystems 67: 1-11.

EKEBERG E; RILEY HCF. 1996. Effects of mouldboard ploughing and direct planting on yield and nutrient uptake of potatoes in Norway. Soil \& Tillage Research 39: 131- 142.

FABEIRO C; OLALLA FMS; JUAN JA. 2001.Yield and size of deficit irrigated potatoes. Agricultural Water Management 48: 255-266.

FERRERAS LA; DE BATTISTA JJ; AUSILIO A; PECORARI C. 2001. Parámetros físicos del suelo en condiciones no perturbadas y bajo laboreo. Pesquisa Agropecuária Brasileira 36: 161-170.

FONTES PCR. 2005. Cultura da batata. In: FONTES PCR. Olericultura: teoria e prática. Viçosa: DFT. p. 323-343.

FONTES PCR. Preparo do solo, nutrição mineral e adubação da batateira. 1997. Viçosa: Universidade Federal de Viçosa. 42p.

MAGLEBY RS; SCHERTZ DL. 1988 Conservation tillage chalks up steady gains. Agriculture Engineering 67: 14-16.

MESQUITA HA; PAULA MB; ALVARENGA MIN; MARIO REGINA S. 1999. Cultura da batata e a preservação ambiental. Informe Agropecuário 20: 20-23.

MILLER DE; MARTIN MW. 1987. The effect o irrigation regime and subsoiling on yield and quality of three potato cultivars. American Potato Journal 64: 17-25.

MUNDY C; CREAMER NG; CROZIER CR; WILSON G; MORSE RD. 1999. Soil physical properties and potato yield in no-till, subsurface-till, and conventional-till systems. HortTechnology 9: 240-247.

OLIVEIRA AD. 2003. Desenvolvimento e avaliação operacional do protótipo UFV-ENG para o plantio direto de batata. Viçosa: DEA - UFV.129 p (Tese doutorado).

PARKER CJ; CARR MKV, NARVIS NJ, EVANS MTB; LEE VH. 1989. Effects of subsoil loosening and irrigation on soil physical properties, root distribution and water uptake of potatoes (Solanum tuberosum). Soil \& Tillage Research 13: 267-285.
PIERCE FJ; BURPEE CG. 1995. Zone tillage effects on soil properties and yields and quality of potatoes (Solanum tuberosum L.). Soil \& Tillage Researc 35: 135-146.

RACHWAL MFG; DEDECEK RA. 1996. Influência da aeração e da disponibilidade hídrica em Cambissolos e Latossolos com diferentes níveis de erosão sobre a produtividade e a qualidade da cultura da batata. Revista Brasileira de Ciência do Solo 20: 485-491.

RILEY H; EKEBERG E. 1998. Effects of depth and time of ploughing on yields of spring cereals and potatoes and on soil properties of a morainic loam soil. Acta Agriculturae Scandinavica - Section B Soil and Plant Science 48: 193-200.

SAINI GR; HUGHES DA. 1972. Soil compaction reduces potato yields. Canadian Agriculture 17: 28-29.

SCHMIDT CP; BELFORD RK. 1994. Increasing the depth of soil disturbance increases yields of direct drilled wheat on the sandplain soil of Western Australia. Australian Journal of Experimental Agriculture 34: 777-781.

SILVEIRA GM. 1997. Tecnologia apropriada em ferramentas, máquinas e implementos agrícolas para pequenas propriedadades rurais: São Paulo. In: TOMIYOSHI CM; SILVA ODRF; CASAO JUNIOR R; DIAS A. (Org.). Tecnologia apropriada em ferramentas, implementos e maquinas agrícolas para pequenas propriedades. Campina Grande: Universidade Federal da Paraíba. p. 226-295.

SLONEKER LL; MOLDENHAUER WC. 1977. Measuring the amounts of crop residue remaining after tillage. Journal of Soil and Water Conservation 32: 231-236.

STURZ AV; CARTER MR; JOHNSTON HW. 1997. A review of plant disease, pathogen interactions and microbial antagonism under conservation tillage in temperate humid agriculture. Soil \& Tillage Research 41: 169189.

YUAN BZ; NISHIYANA S; KANG Y. 2003. Effects of different irrigation regimes on the growth and yield of drip-irrigated potato. Agricultural Water Management 63: 153-167. 